\title{
Efficiency, Economic and Environmental Assessment of Ground-Source Heat Pumps in Central Pennsylvania
}

\author{
Seth Blumsack, Jeffrey Brownson and Lucas Witmer
}

\begin{abstract}
The energy use of a ground-source heat pump (GSP) for heating, cooling and hot water in a Central Pennsylvania residence (namely, the author's house) is analyzed, compared to a simulation of electricity and a heating-oil furnace (with electric cooling) for these same energy uses. Energy demands for space conditioning in the house are simulated by building a model of the house using the Transient Energy System Simulation (TNRSYS) tool. Overall, the efficiency gain for the ground-source heat pump compared to electricity is $43 \%$ for cooling and $81 \%$ for heating. For home heating and hot water, the ground-source heat pump has a $42 \%$ efficiency gain over a fuel-oil furnace. The system modeled in this paper has a payback period of between four and five years compared to an all-electric system. The payback period compared to a hybrid system of fuel-oil heat and electric cooling is between two and three years.
\end{abstract}

Index Terms-Ground-source heat pump, energy efficiency, distributed energy

\section{INTRODUCTION}


eothermal energy is most often associated with steam extracted from subterranean reservoirs for the generation of central-station electricity. Since these steam reservoirs are generally only found in geologically active areas (around fault lines or active volcanoes), the use of geothermal energy for electric power has naturally been limited. Where moderate geothermal resources are located, the steam has been used for distributed energy applications, such as district heating. A more widespread potential use of geothermal energy is for single-building residential heating and cooling via a groundsource heat pump. This application ties the residence to an electricity source to operate the heat pump, but since the climate-control energy itself comes from the earth, geothermal heat pumps have the potential for significant energy savings [1].

The performance of ground-source heat pumps for residential building applications has been studied in various controlled experiments in Turkey by Arif Hebpasli [2 - 5]. A simulation model developed for a Canadian climate in [6]

Seth Blumsack is with the Department of Energy and Mineral Engineering, The Pennsylvania State University, University Park, PA 18602 (e-mail: blumsack@psu.edu).

Jeffrey Brownson is with the Department of Energy and Mineral Engineering, The Pennsylvania State University, University Park, PA 18602 (e-mail: nanomech@psu.edu).

Lucas Witmer is with the Department of Energy and Mineral Engineering, The Pennsylvania State University, University Park, PA 18602 (e-mail: ltw110@psu.edu). suggests that ground-source heat pumps are "economically preferable" [6] to conventional energy sources, in the sense of having a higher net present value.

Rather than setting up a laboratory experiment, this paper attempts to estimate the relative efficiency and payback period of a ground-source heat pump used for space conditioning and hot water in an actual Central Pennsylvania single-family residence. This location is of interest for two reasons. First, as discussed in Section III, the region has four distinct seasons, with warm humid summers and relatively cool winters. The system performance discussed here might thus be thought of as "typical" for the Mid-Atlantic U.S., which has a high population density and relatively high residential energy costs. The second point of interest is that the residence discussed in this paper belongs to one of the authors, who is naturally curious whether the ground-source heat pump in his home is merely a curiosity to be discussed at cocktail parties, or represents a sound economic investment.

Three energy-source scenarios are modeled in this paper. The first uses the ground-source heat pump for all space conditioning and most hot water (electric resistance heating provides about $30 \%$ of the energy for hot water). The other two scenarios use electricity for all heating and cooling; and a hybrid system of electric cooling and fuel-oil heating. The ground-source heat pump provides a significant efficiency gain over either system. For heating, the ground-source heat pump is $42 \%$ more efficient than the fuel-oil furnace and $81 \%$ more efficient than electric heat. The efficiency gain over electric cooling is $43 \%$.

\section{Ground-Source Heat Pump Technology}

A ground-source heat pump functions nearly identically to an air-source heat pump or other heat exchanger, except that it uses the earth as its energy source. In most locations, the frost line extends several feet beneath the surface, meaning that the ground below maintains an essentially constant temperature throughout the year. In Centre County, Pennsylvania, where the house is located, the frost line is estimated to be around 36 inches [7] and the ground temperature beneath the frost line is approximately $55^{\circ} \mathrm{F}$.

Most ground-source heat pump applications are closed-loop systems (open-loop and pond systems are discussed in [1]). When called upon to provide space heating, a non-toxic chemical heat exchanger such as glycol is pumped through one or more parallel loops of underground piping (typically polyethylene). The basement furnace captures the heat and 
distributes it through the ductwork in the home. ${ }^{1}$ For cooling purposes, the process is essentially reversed - warm air is extracted from the home and exchanged into the earth through the same piping loop. During the summer when the unit is used for cooling, most ground-source heat pumps capture some of the waste heat extracted from the house (via a desuperheater) and use it to heat water. Many can also provide water heating in the winter by using a separate heat exchanger. $^{2}$
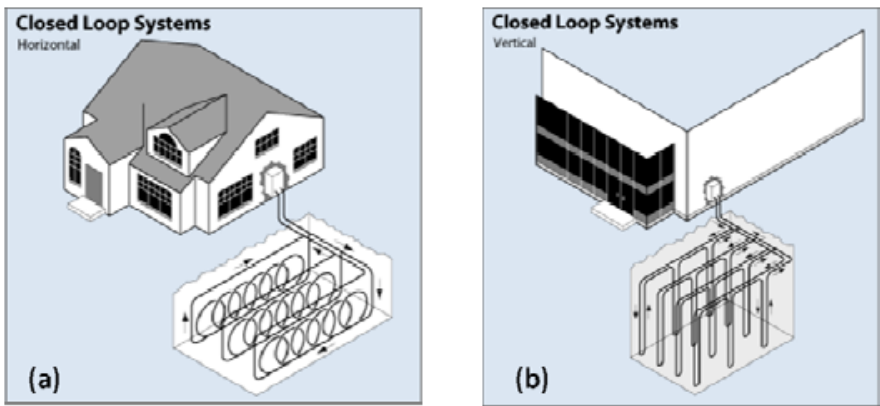

Figure 1: Ground-source heat pump closed-loop configurations. Panel (a) depicts a horizontal configuration, while panel (b) depicts a vertical configuration. Source: [1]

The piping is either arranged in a "horizontal" configuration, parallel to the plane of the ground (Figure 1a), or in a "vertical" configuration, normal to the plane of the ground (Figure 1b). The choice of a horizontal or vertical configuration is generally driven by the amount of land available and the character of the soil. Typically, a horizontal pipe network requires more land and is laid 12 to 24 inches below the frost line. In a vertical configuration, a number of holes between 50 and 400 feet deep are bored in the earth, roughly five meters apart. A vertical pipe network is generally used for larger buildings (where the land requirements for a horizontal network would be prohibitive) and in locations with poor quality (rocky or clayey) soil. Either configuration does require sufficient property rights (surface and subsurface) to accommodate the network of pipes, which may limit the practicality of ground-source heat pumps in high-density urban areas where land may not be available, or where subsurface excavation is problematic due to existing underground civil infrastructures (such as water and gas distribution mains).

\section{THE HOUSE AND ITS ENVIRONS}

The residence used as a case study in this paper is a 3,600square-foot single-family dwelling in Centre County, Pennsylvania (2,800 square feet above ground). The home was built in 2004 (it was purchased by the author in 2007),

\footnotetext{
${ }^{1}$ The fact that the ground-source heat pump requires ductwork for distribution throughout the home does limit its applications. Retrofitting older homes for geothermal heat, for example, may be cost-prohibitive.

${ }^{2}$ The house analyzed in this paper has an air ventilator system that captures stale air from indoors and brings in fresh air from the outdoors. The manufacturer of the unit, April-Aire, claims that the unit also assists in energy recovery by capturing $40 \%$ of the heat in the stale air during the winter months, before sending it outside. Since the author has not been able to verify these claims, the ventilator system is ignored in the modeling presented in this paper.
}

and the ground-source heat pump was installed at the time of construction. Although the house sits on 11 acres of farmland, the rocky quality of the soil necessitated a vertical closed-loop pipe configuration for the heat pump. There are four 150-foot wells located on the property.

The house is framed with 2x6 construction, with wood clapboard siding and shingles, and is insulated with spray icynene foam. All windows in the house are double-paned with low-emissivity coating. Based on materials supplied by the builder (also the original owner), the home has an overall $R$-value of $30 .^{3}$

Centre County is located in the geographic center of Pennsylvania, amongst a series of long, steep ridges and broad valleys known as the Allegheny Plateau. This portion of Pennsylvania has a fairly humid continental climate. The rugged and heavily forested terrain at (relatively) high elevations keeps summer high temperatures from reaching the extremes seen in nearby cities (such as Philadelphia and Washington, DC), while the terrain contributes to aboveaverage rainfall [10].

A 25-year average monthly temperature for State College (the largest municipality in Centre County), along with the 25year monthly extreme temperatures (highs and lows) is shown in Figure 2.

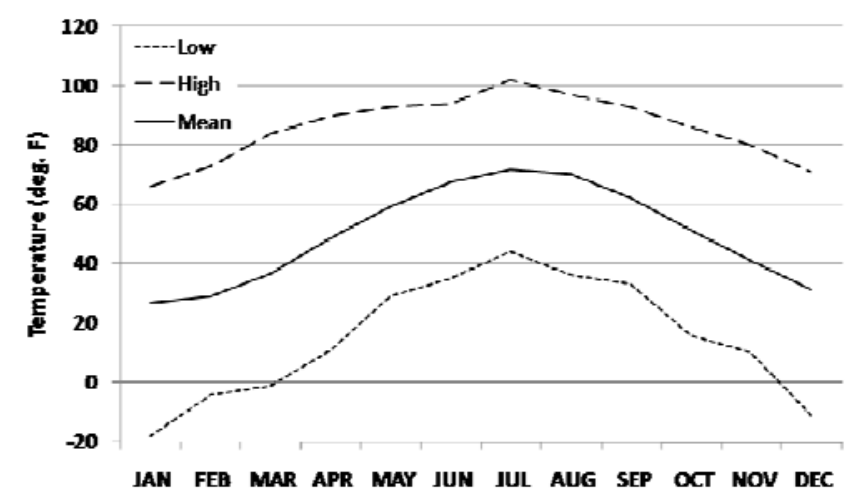

Figure 2: 25-year monthly average temperatures in State College, PA. Source: National Climactic Data Center.

\section{Modeling the Relative EfFiciency of THE Ground- SOURCE HEAT PUMP SYSTEM}

For the one-year period June 2007 through May 2008, we run a series of simulations to estimate the energy consumed for space conditioning and water heating in the simulated house, under three scenarios:

1. The ground-source heat pump is used for all space conditioning and almost all water heating. More specifically, we assume that the heat pump can only heat the water to 100 degrees, with electric resistance

\footnotetext{
${ }^{3}$ From the materials supplied by the builder, it is not completely clear whether the $R$-value of 30 is a "whole-house" $R$-value or a "whole-wall" $R$-value. The Icynene manufacturer [8] claims that its insulation sprayed into 2x6 framing has an aggregate $R$-value of 26 . However, much of the wall space bordering the outdoors is taken up by windows, which have much lower $R$-values (around $R$-3, according to [9]).
} 
heating required to heat the water an additional 25 degrees. This represents the "base case" set of simulations and is similar to the configuration that currently exists in the house.

2. Electricity is used for all space conditioning and water heating. We will refer to this scenario as the "allelectric" scenario.

3. Electricity is used for cooling, but a modern fuel-oil furnace with an efficiency of $85 \%$ is used to provide heating and hot water. We will refer to this scenario as the "oil heat" scenario.

For each of the three scenarios, we assume a summer indoor temperature setpoint of $T^{*}=74$ degrees around the clock. The winter temperature setpoint is assumed to be time-varying, as shown in Figure 3. The figure shows that we keep the house heated to 75 degrees during the day in the wintertime (or whenever heating is required), with short ramp-ups and rampdowns in the early morning and evening. ${ }^{4}$

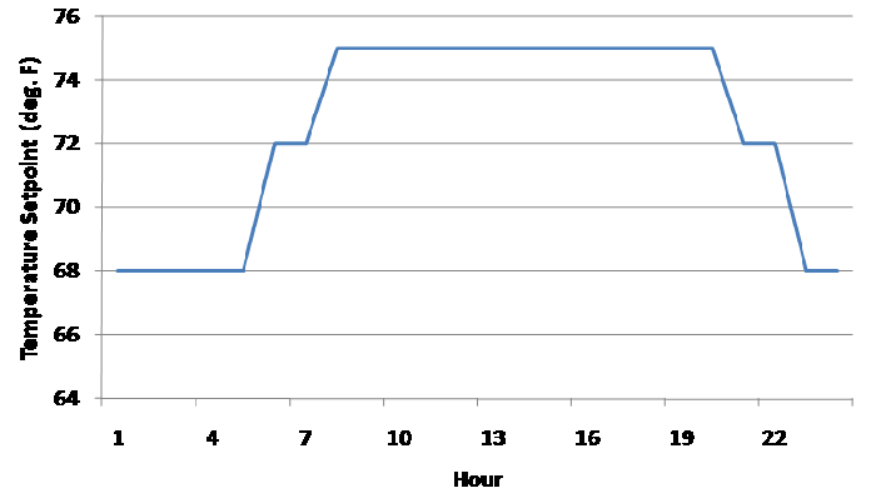

Figure 3: Winter thermostat set-points in the house.

Figure 4 shows electricity use in the house over the course of one year, along with the total electric bill (at 7.33 cents per $\mathrm{kWh}$ plus a $\$ 5$ monthly fixed distribution charge), beginning in June 2007. The usage data in the figure came from the homeowner's monthly electric bill. The house does not have an oil furnace, nor is there a natural gas distribution network in the area of Pennsylvania where the house is located. ${ }^{5}$

\section{A. The Demand for Space Conditioning}

Heat transfer in and out of the home is modeled here as entirely conductive. Since the home is fairly well insulated, infiltration (leakage through seals in doors and windows) is not likely to be a significant source of heat transfer. Radiation may play a more significant factor in heat loss, since the icynene insulation is not foil-backed, but is neglected here.

Heat flux in and out of the house is governed by the following process [11]:

\footnotetext{
${ }^{4}$ The winter indoor temperature setpoint of 75 degrees may strike the reader as quite high, perhaps even bordering on profligate. The only defense offered by the author is that lower indoor temperatures would threaten the orchids being grown in the house.

${ }^{5}$ The furnace for the ground-source heat pump does have a backup $10 \mathrm{~kW}$ electric strip heater as a backup (or supplement, in the case of very cold weather). The strip heater has not been used since the author moved into the house.
}

$\dot{Q}=\frac{A \times \dot{M}}{R}$,


Figure 4: Monthly electricity usage and total cost from the author's electricity bills.

where $Q$ represents heat loss in or out of the home (thus, $\dot{Q}$ represents heat loss per unit time), $A$ is the area of the conductive surface, in square feet, $M$ is the temperature difference (indoor temperature less outdoor temperature), in degrees Fahrenheit and $R$ is the $R$-value of the conductive surface, and takes units of $\mathrm{ft}^{2} \times{ }^{\circ} \mathrm{F} \times[$ time $] \times \mathrm{BTU}^{-1}$. A positive value for $\dot{Q}$ indicates demand for heating (heat is escaping from the house), while a negative value for $\dot{Q}$ indicates a demand for cooling (warm air is leaking into the house).

While the house has 3,600 square feet of living space, 800 square feet are subterranean (the basement) and are not climate-conditioned. The above-ground living spaces have eight-foot ceilings; the ceiling height on the top floor is 20 feet above ground. The outside dimensions of the house are 42 feet by 32 feet. The simulation model we build for the house incorporates the effects of the interior layout (location of rooms and walls) as well as the ceiling heights on both the first and second floors, as well as the attic.

\section{B. The Demand for Hot Water}

When the house is being cooled, the heat pump captures warm air from the house and uses it to heat water, by means of a desuperheater. During the winter, the heat pump is able to provide hot water in addition to warm air using an auxiliary heat exchanger. Warm water from the heat pump is stored in an insulated holding tank (not connected to an electric heater) 
at a temperature of $100^{\circ} \mathrm{F}$. As hot water is called for, the water is transferred from the holding tank to a standard hot-water tank with electric resistance heating, where it is heated to $120^{\circ} \mathrm{F}$. Since water enters the system at the ground temperature of $55^{\circ} \mathrm{F}$, the heat-pump system supplies $70 \%$ of the necessary energy, while electricity supplies the remainder.

The water's temperature change is governed by [11 - 13]:

$$
m \times S H_{w} \times \dot{T}_{w}=U A \times\left(T_{b a s}-T_{w}\right)+\dot{Q},
$$

where $m$ is the mass of water (lb), $S H_{w}$ is the specific heat of water $\left(\mathrm{BTU} \times{ }^{0} \mathrm{~F}^{-1} \times \mathrm{hr}^{-1}\right), T_{w}$ is the temperature of the water in the tank $\left({ }^{\circ} \mathrm{F}\right), T_{\text {bas }}$ is the ambient temperature in the basement (set at $67^{\circ} \mathrm{F}$ year-round), $U A$ is an insulation factor governing how quickly the water in the tank cools (analogous to the $R$ value for house insulation), and $Q$ is the heat energy provided to the tank (BTU). The hot water heater in the house is assumed to have a $U A$ factor of 2.5 .

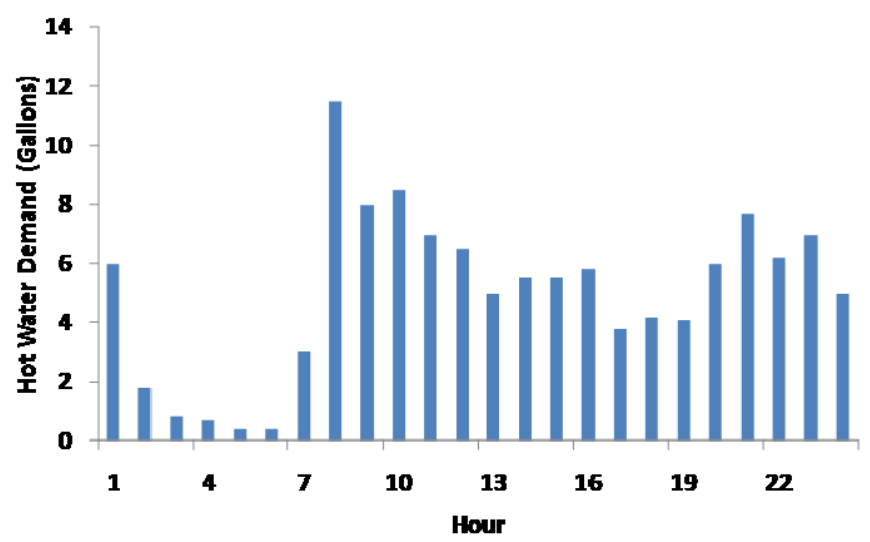

Figure 5: Average hourly hot water usage for an American family. Source: [14]

In this paper we assume that hot water usage in the house is similar to that of a typical American family [14], as shown in Figure 5. We do not differentiate between water used for different applications (such as showering and washing dishes), each of which may require water that is "more hot" or "less hot." I assume that all hot water use represents demand for 120-degree water.

\section{Simulation Procedure and System Information}

The simulations in this paper are run over hourly time scales for the period June 1, 2007 to May 31, 2008. During each hour, the heat loss in the home (that is, the amount of heating or cooling required for that hour) is calculated using a model of the house built with a simulation tool called the Transient Energy Systems Simulation tool (TRNSYS). TRNSYS is a modular tool built in FORTRAN. ${ }^{6}$ Heat loss is measured in units of BTU per hour. The temperature difference $M$ is given by:

$$
M(t)=T_{\text {set }}(t)-T_{\text {app }}(t),
$$

Where $T_{\text {set }}$ is the thermostat setpoint at time $t$, as discussed above and shown in Figure 3, and $T_{a p p}$ is the apparent outdoor temperature in State College, PA at time $t$, as recorded by the National Climactic Data Center.

Total energy demanded in each hour (in BTU) is the sum of the energy required for space conditioning plus the sum of the energy required for hot water. The ground-source heat pump has an hourly capacity of 42.1 MBTU for cooling and 29.8 MBTU for heating. During some hours, the total energy demanded may exceed the capacity of the ground-source heat pump. In this case, the simulations require this excess demand to be met in the following hour. In equation form, the total energy demand $Q_{\text {tot }}(t)$ in hour $t$ is written:

$$
Q_{\text {tot }}(t)=\left\{\begin{array}{c}
\max \left(Q_{\max }(t), Q_{\text {air }}(t)+Q_{w}(t)\right) \\
\text { if } \quad Q_{\text {tot }}(t-1) \leq Q_{\max }(t-1) \\
\max \left(\begin{array}{l}
Q_{\max }(t), Q_{\text {air }}(t)+Q_{w}(t) \\
+\left[Q_{\text {tot }}(t-1)-Q_{\max }(t-1)\right]
\end{array}\right) \\
\text { if } \quad Q_{\text {tot }}(t-1)>Q_{\max }(t-1)
\end{array},\right.
$$

where $Q_{\text {air }}$ is the hourly energy demand for space conditioning, $Q_{w}$ is the hourly energy demand for hot water and $Q_{\max }$ is the hourly energy output capacity of the energy system.

The heating season is assumed to run from November through May each year, while the cooling season is assumed to run from June through October. In the simulations, no cooling is demanded during the heating season, and no heating is demanded during the cooling season.

The ground-source heat pump system modeled is a Trane GSUJ-042 with an EER rating of 18 and a corresponding COP of 5.3. The cost of the system, including installation is assumed to be $\$ 12,000$. The all-electric scenario assumes electric heating and cooling with an EER rating of 10.3 (the average rating for Energy Star air conditioners) at a total cost of $\$ 6,000$. The oil furnace system is assumed to have a heating efficiency of $85 \%$ (cooling efficiency is identical to the all-electric scenario) and a total cost of $\$ 5,000$.



Figure 6: Heat rate curve for fossil generators in the PJM system.

\footnotetext{
${ }^{6}$ More information on TRNSYS is available at www.trnsys.com.
} 
Since all three systems rely on the electric grid to some degree, the total system efficiency will be influenced by the efficiency with which electricity is generated at central-station power plants. We assume that all electricity for each system is purchased from plants in the PJM system, and we measure the efficiency of the generating plants in PJM using published data on average heat rates for fossil generation [15]. The heat rate curve for PJM is shown in Figure 6.

We measure the generation efficiency for the grid power required by each home energy system in two ways. The first way is to simply use an average heat rate for all fossil generation in the PJM system. This simple average is equal to $12,335 \mathrm{BTU} / \mathrm{kWh}$. The second method is to build an economic dispatch curve for PJM, and determine the heat rate of the marginal generator dispatched in each hour using the method described in [16]. Particularly over the course of a year, whether the efficiency of the PJM system is calculated on an average or marginal basis does not materially affect the simulation results.

\section{Simulation Results AND Discussion}

This section contains the results of the hourly energy-use simulations. The ground-source heat pump system is compared to the all-electric system and the fuel-oil heating system (with electric cooling) in terms of total energy use, relative efficiency and cost.

\section{A. Energy Use and Relative Efficiency}

This section contains the results of the hourly energy-use simulations. The ground-source heat pump system is compared to the all-electric system and the fuel-oil heating system (with electric cooling) in terms of total energy use, relative efficiency and cost.

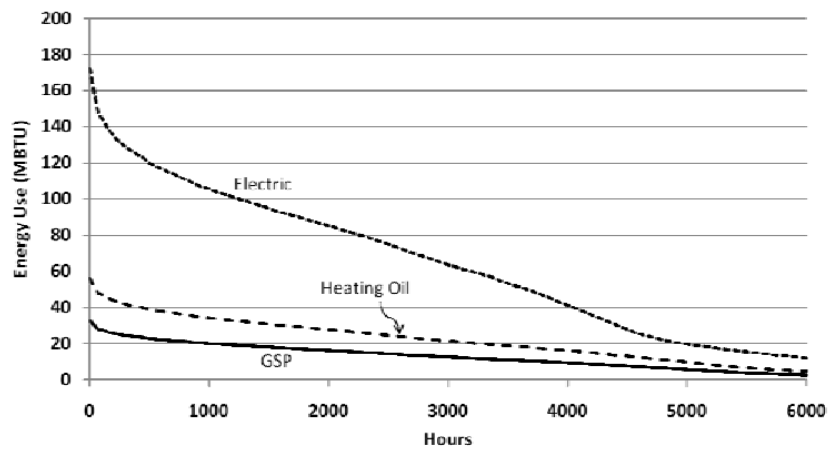

Figure 7: Cumulative energy use distribution curves for the three home energy systems over the course of one year. GSP denotes the ground-source heat pump system. The horizontal axis stops at 6,000 hours because of a large number of hours where energy demand is close to zero.

Figure 7 shows a cumulative distribution function for hourly energy use in each of the three simulated systems, while Figure 8 shows a cumulative distribution function for the hourly differences in total energy use. Generation efficiency for power purchased from the PJM system is calculated using the "average heat rate" methodology. The figure demonstrates that the all-electric system is by far the least energy-efficient. The energy-intensive nature of electric heating, relative to fuel oil, is the primary contributor to the overall inefficiency of the electric system versus the groundsource heat pump. For heating and hot water, the groundsource heat pump is $42 \%$ more efficient than the fuel-oil system and $81 \%$ more efficient than the electric heating system. For cooling, the ground-source heat pump is $43 \%$ more efficient than the electric cooling system (used in both the all-electric and fuel-oil scenarios).

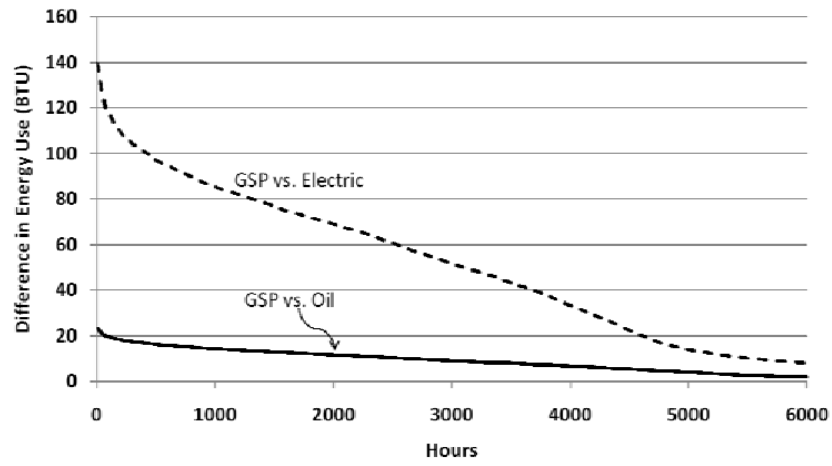

Figure 8: Cumulative distribution curves for the hourly difference between the ground-source heat pump (GSP) energy use and the energy use of the allelectric and oil-heat systems. The horizontal axis stops at 6,000 hours because of a large number of hours where energy demand is close to zero.

\section{B. Economics of Ground-Source Heat Pumps}

For each hour, the cost of primary energy to run each of the three systems was calculated. The assumed cost of fuel oil was $\$ 4$ per gallon. The total cost of electricity is the sum of four different components: generation, transmission, distribution and ancillary services. These costs are disaggregated based on information in the author's monthly bill from Allegheny Power, and shown in Table 1. The monthly bill also includes taxes and a fixed distribution charge, which are neglected in this analysis.

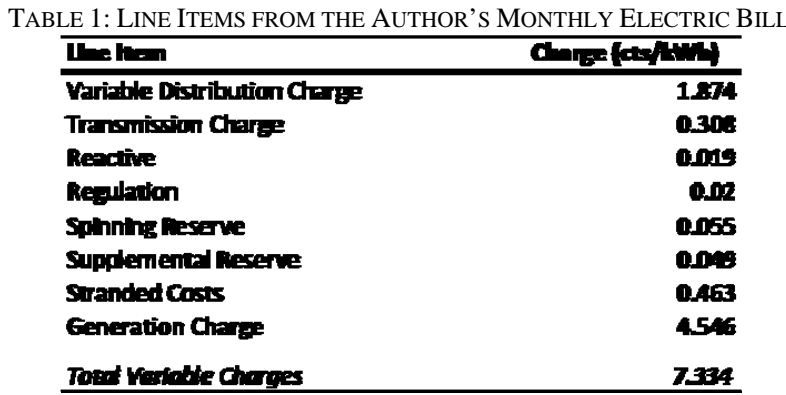

We calculate the total cost of electricity required for space conditioning and hot water under two different assumptions. The first assumption is that the generation charge is regulated, based on the cost of service. ${ }^{7}$ The second assumption is realtime pricing: the generation charge for each hour is equal to the locational marginal price (LMP) in the Allegheny Power

\footnotetext{
7 This is the assumption reflected in the charges shown in Table 1. Allegheny Power will not transition out of regulated retail pricing until January 1, 2011.
} 
Zone of PJM. ${ }^{8}$ The transmission, distribution and ancillary services costs are identical under both assumptions. ${ }^{9}$

The total annual primary energy cost for each home energy scenario is shown in Table 2. The annual costs of the groundsource heat pump are lower than the all-electric system by roughly a factor of six, and are lower than the oil-heat system by more than a factor of nine. Note that even though the oilheat system is more efficient than the all-electric system (see Figures 7 and 8), the consumer costs of the oil-heat system are nearly $50 \%$ higher than the all-electric system.

\begin{tabular}{lcr} 
TABLE 2: ANNUAL COSTS OF EACH HOME ENERGY SYSTEM \\
\hline & \multicolumn{2}{c}{ Annual Cost (\$) } \\
\hline \hline Geothermal (flat rate) & $\mathbf{\$}$ & $\mathbf{4 8 1 . 3 8}$ \\
Geothermal (LMP) & $\mathbf{\$}$ & $\mathbf{5 5 7 . 0 1}$ \\
Electric (flat rate) & $\mathbf{\$}$ & $\mathbf{2 , 3 8 4 . 8 4}$ \\
Electric (LMP) & $\mathbf{\$}$ & $\mathbf{2 , 7 0 6 . 2 1}$ \\
Oil (flat ratr)* & $\mathbf{\$}$ & $\mathbf{3 , 7 1 5 . 6 5}$ \\
Oil (LMP)* & $\mathbf{\$}$ & $\mathbf{3 , 7 5 3 . 5 7}$ \\
\hline * Oil fumace heat with electric cooling.
\end{tabular}

To calculate whether the lower energy costs of the groundsource heat pump system are worthwhile, I calculated the present discounted value of the costs of each system over a period of ten years, assuming that energy costs and our hourly usage remain constant in each year. The capital cost of each system was assumed to be incurred in year zero (and thus is not discounted), while the energy costs of each system were discounted annually, with a discount rate of $5 \%$.

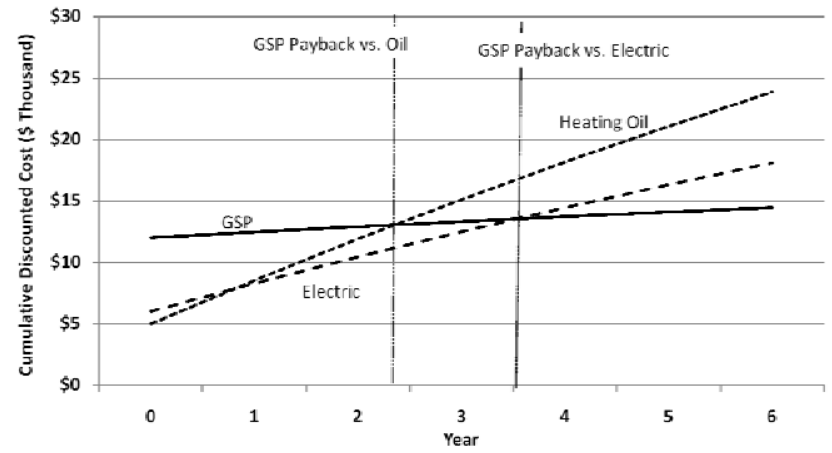

Figure 9: Present discounted cost of each home energy system, assuming the flat regulated generation charge from Table 1. GSP denotes the groundsource heat pump system. Crossover points denote the payback period of the ground-source heat pump system and other systems.

The cumulative present discounted costs of each system are shown in Figure 9, assuming a flat discounted electric generation rate, and in Figure 10, assuming real-time pricing. The intersection of the discounted cost curve for the ground-

\footnotetext{
${ }^{8}$ As discussed in [16], under real-time pricing consumers will see significantly higher bills during periods of peak usage and are likely to respond in some way to these higher bills. In this analysis, we neglect the effects of a nonzero price elasticity of demand and assume that energy usage remains unchanged.

${ }^{9}$ PJM currently uses market-based pricing for some ancillary services. We are thus assuming that the charges for ancillary services will remain at their current levels.
}

source heat pump (denoted GSP) with the curves for the other two systems determines the payback point for the groundsource heat pump. Under flat-rate pricing of electric generation, the ground-source heat pump pays for itself during its second year of operation, compared to the oil-heat system. The payback period relative to the electric heat system is between three and four years. Since LMPs in the Allegheny Zone of PJM are, on average, higher than my current regulated generation rate, the payback periods under real-time pricing of electricity are slightly shorter, as shown in Figure 10.

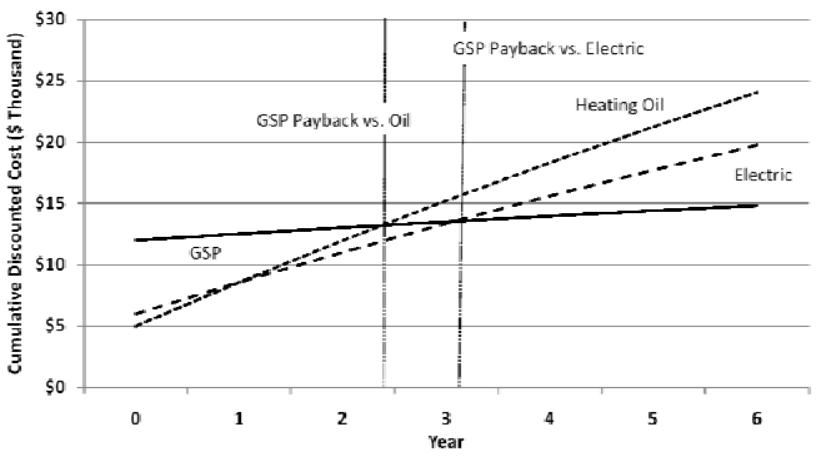

Figure 10: Present discounted cost of each home energy system, assuming real-time pricing of electricity. GSP denotes the ground-source heat pump system. Crossover points denote the payback period of the ground-source heat pump system and other systems.

\section{ENVIRONMENTAL IMPACTS}

Our simulation results in Section V demonstrate that the ground-source heat pump system requires significantly less input energy than either the all-electric system or the hybrid system of fuel-oil heating and electric cooling. Based on the results of our energy-use simulations, we can estimate the emissions reductions associated with the ground-source heat pump system relative to the other two systems.

We focus on emissions of carbon dioxide $\left(\mathrm{CO}_{2}\right)$, sulfur dioxide $\left(\mathrm{SO}_{2}\right)$, and the various oxides of nitrogen $\left(\mathrm{NO}_{\mathrm{x}}\right)$. We also investigated the potential for reduced mercury emissions, but the magnitudes of mercury involved for a single household are so small that any comparison of energy systems was not enlightening. Average annual emissions data for the PJM electricity system (in pounds of pollutant per MWh of generation) are taken from [15]. We calculate an average emissions factor for each pollutant for the whole PJM system, weighted by generator size and capacity factor. The resulting average emissions rates used in this portion of the analysis are $2.21 \mathrm{lbs} / \mathrm{MWh}$ of $\mathrm{NO}_{\mathrm{x}}, 8.51 \mathrm{lbs} / \mathrm{MWh}$ of $\mathrm{SO}_{2}$ and $1,256.08$ $\mathrm{lbs} / \mathrm{MWh}$ of $\mathrm{CO}_{2}{ }^{10}$

Burning fuel oil also results in $\mathrm{CO}_{2}$ and $\mathrm{NO}_{\mathrm{x}}$ emissions. In our analysis we use figures from the U.S. EPA of 161.44 $\mathrm{lbs} / \mathrm{MMBTU}$ of $\mathrm{CO}_{2}$ and $0.376 \mathrm{lbs} / \mathrm{MMBTU}$ of $\mathrm{NO}_{\mathrm{x}}$. [17]

Using these figures, we calculate the hourly emissions footprint of the home under each of the three energy systems. The results are summarized in Table 3, which shows annual

\footnotetext{
${ }^{10}$ We calculate an average emission rate of $0.04 \mathrm{lb} / \mathrm{GWh}$ for mercury. At the level of a single household, the mercury footprint will be so small that we omit mercury from our emissions analysis.
} 
emissions of $\mathrm{CO}_{2}, \mathrm{SO}_{2}$ and $\mathrm{NO}_{\mathrm{x}}$ from energy use for space conditioning and hot water in the house. Note that Table 3 does not include energy use for other purposes such as lighting, nor does it include the emissions impacts of transportation, since we assume that these energy uses would remain constant, no matter what system was used for space conditioning and hot water.

TABLE 3: EMISSIONS IMPACTS FROM EACH ENERGY SYSTEM FOR SPACE CONDITIONING AND HOT WATER (SHORT TONS/YEAR)

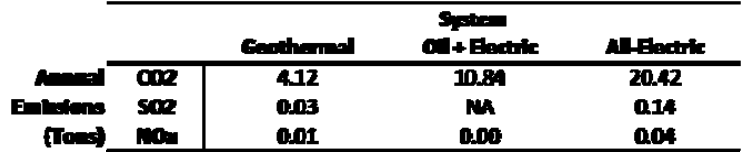

The GSP system reduces $\mathrm{CO}_{2}$ emissions by more than half compared to the hybrid system of heating oil and electric power, and by a factor of five compared to the all-electric system. Emissions of $\mathrm{SO}_{2}$ and $\mathrm{NO}_{\mathrm{x}}$ are reduced by similar magnitudes, though the total emissions of these two pollutants from household energy use are orders of magnitude smaller than $\mathrm{CO}_{2}$. In the event that the U.S. begins to tax or otherwise price carbon dioxide emissions at the consumer level, the GSP system would offer additional savings.

\section{CONCLUSIONS AND FUTURE WORK}

Despite up-front capital costs that are more than double those of oil-heat or all-electric home energy systems, the ground-source heat pump appears to have been a fairly good investment. Using a detailed simulation model of energy use for climate control and hot water in a Central Pennsylvania single-family home, we found that the ground-source heat pump has yielded significantly lower costs and higher efficiencies. Emissions related to space conditioning and hotwater heating in the home are reduced significantly compared to the fuel-oil or all-electric systems.

Particularly for suburban and rural areas, ground-source heat pumps have the potential to lower both average and peak energy costs for homeowners and small commercial customers (whether these systems are appropriate for larger customers is an interesting question, but beyond the scope of this paper). Usage of these systems also lowers stress on the electric transmission and distribution infrastructures, which may lower the risk of localized or widespread electric service interruptions. Ground-source heat pumps are not, however, a silver bullet. The land requirements, even for small systems with vertical closed-loop configurations, may be prohibitive in high-density urban areas. In addition, the system as modeled requires either new construction or existing ductwork to be cost-effective. The costs of retrofitting existing homes (particularly older homes) will affect the economics of ground-source heat pumps and likely varies widely based on location.

\section{ACKNOWLEDGMENT}

The authors thank David Riley and Jeff Rayl for helpful comments and suggestions, and Erin Whiting for allowing us to publicize the fact that she heats the house to 75 degrees in the wintertime.

\section{REFERENCES}

[1] U.S. Department of Energy, Office of Energy Efficiency and Renewable Energy, "Buyer's Guide to Geothermal Heat Pumps," http://www.eere.energy.gov/consumer/your_home/space_heating_coolin g/index.cfm?mytopic $=12640$

[2] A. Hepbasli, O. Akdemir, and E. Hancioglu, 2003. "Experimental Study of a Closed Loop Vertical Ground Source Heat Pump System,” Energy Conversion and Management 44:4, pp. 527 - 548.

[3] A. Hepbasli and O. Akdemir, 2004. "Energy and Exergy Analysis of a Ground Source Heat Pump,” Energy Conversion and Management 45:5, pp. $737-753$.

[4] O. Ozgener and A. Hepbasli, 2004. "Experimental Performance Analysis of a Solar-Assisted Ground-Source Heat Pump Greenhouse Heating System,” Energy and Buildings 37:1, pp. $101-110$.

[5] O. Ozgener and A. Hepbasli, 2005. "Exergoeconomic Analysis of a Solar Assisted Ground-Source Heat Pump,” Applied Thermal Engineering 25:10, pp. 1459 - 1471.

[6] P. F. Healy and V. I. Ugursal, 1998. "Performance and Economic Feasibility of Ground-Source Heat Pumps in a Cold Climate," International Journal of Energy Research, 21:10, pp. 857 - 870.

[7] Northeast Regional Climate Center, Atlas of Soil Freezing Depth Extremes for the Northeastern United States.

[8] Icynene Corporation product specifications, available at http://www.icynene.com/assets/documents/PDFs/Spray_and_Pour_Form ulas.pdf.

[9] U.S. Department of Energy, Office of Energy Efficiency and Renewable Energy, "The R-Value of Insulation," www.eere.energy.gov/consumer/your_home/insulation_airsealing/index. $\mathrm{cfm} /$ mytopic $=11340$

[10] National Climactic Data Center, "Pennsylvania Climate Narrative." Available at climate.psu.edu/data/ncdc_pa.pdf.

[11] D. Q. Kern, 1990. Process Heat Transfer, McGraw-Hill.

[12] N. P. Chopey, 1994. Handbook of Chemical Engineering Calculations, McGraw-Hill.

[13] C. H. K. Goh and J. Apt, 2004. "Consumer Strategies for Controlling Electric Water Heaters Under Dynamic Pricing," Carnegie Mellon Electricity Industry Center working paper CEIC-04-02.

[14] ASHRAE, 1995. ASHRAE Handbook: Heating, Ventilating and Air Conditioning, Typical Residential Family's Hourly Hot Water Use, at p. 45.10 .

[15] Environmental Protection Agency, Emissions \& Generation Resource Integrated Database (eGRID), available at http://www.epa.gov/solar/egrid/index.htm.

[16] A. Newcomer, S. Blumsack, J. Apt, L. B. Lave and M. G. Morgan, 2008. "The Short Run Economic and Environmental Effects of a Carbon Tax on U.S. Electric Generation,” Environmental Science and Technology 42:9, pp. 3139 - 3144.

[17] U.S. Environmental Protection Agency, 2008. "U.S. Greenhouse Gas Inventory,”http://epa.gov/climatechange/emissions/usinventoryreport.html.

\section{BIOGRAPHIES}

Seth Blumsack is Assistant Professor of Energy and Mineral Engineering at The Pennsylvania State University, University Park PA. He received the M.S. degree in Economics from Carnegie Mellon in 2003 and the Ph.D. in Engineering and Public Policy from Carnegie Mellon in 2006. His main interests are regulation and deregulation of network industries, transmission planning and pricing, and complex networks and systems, especially for energy and electric power.

Jeffrey Brownson is Assistant Professor of Energy and Mineral Engineering at The Pennsylvania State University, University Park PA. He received his Ph.D. from The University of Wisconsin in 2006. His research interests are in the areas of inorganic materials for advanced photovoltaics.

Lucas Witmer is a MS student in Energy and Mineral Engineering at The Pennsylvania State University, University Park PA. 